\title{
Recent Advances in the Microbiology of the Built Environment
}

\author{
Theodore Konya • James A. Scott
}

Published online: 29 March 2014

(C) Springer International Publishing AG 2014

\begin{abstract}
It has been just over three centuries since Antonie van Leewenhoek first conclusively documented the biological nature of the elements of air and dust in the built environment [1]. During the 20th century, advancements in sampling instrumentation and analysis techniques yielded a large literature on the microbiology of air and dust, mainly using culture and microscopy $[2,3]$. In the past few decades, the measurement of health-relevant biochemicals such as allergens, endotoxin, and glucan in the context of population health studies has contributed substantially to our understanding of how the built environment can influence health. In the past few years, investigations of the built environment using cultureindependent sequence-based analysis have confirmed many previously held expectations about the sources and fates of indoor microbes, and in the process, these methods have also produced several unexpected insights into the indoor microbiome. Perhaps not surprisingly, the biological composition of air and dust appears to be vastly more complex than formerly thought. Over the next decade, molecular metagenomic methods are likely to revolutionize our understanding of the roles of air and dust in the biology of life on earth, and in the process, provide sophisticated new tools to elucidate health-environment interactions. This review summarizes recent key studies on the microbiology of the built environment to date using modern culture-independent methods, and considers the implications of these findings
\end{abstract}

T. Konya $\cdot$ J. A. Scott $(\bowtie)$

Division of Occupational and Environmental Health, Dalla Lana School of Public Health, University of Toronto, 223 College Street, Toronto, ON M5T 1R4, Canada

e-mail: james.scott@utoronto.ca

J. A. Scott

Sporometrics Inc., 219 Dufferin Street, Suite 20-C, Toronto,

ON M6K 1Y9, Canada and future studies elucidating the interactions between the humans and the built environment.

Keywords Microbial biogeography $\cdot$ rRNA metagenomics · Built environment $\cdot$ House dust $\cdot$ Indoor mold $\cdot$ Bacteria

\section{Introduction}

The microbial communities of the indoor built environment were amongst the first such habitats to be studied [1], and have since remained a subject of great interest both in the scientific $[2,3]$ and popular literature $[4,5]$. The study of the biological composition of dust also has a lengthy history [6], with very early recognition that humans influence indoor microbial populations [7], and conversely, that indoor microbes influence human health [8]. Since the late 20th century, the traditional study methods of culture and microscopy have been supplemented by measurements of health-relevant biochemicals such as endotoxin, glucan, and allergens in population health research in an effort to better understand the environmental contribution to disease.

Emerging technologies such as high-throughput DNA sequencing have recently made possible the low-cost, comprehensive, culture-independent characterization of the microbiota (i.e., collective microbiological content) of a broad range of media, providing a highly resolved picture of the microbial dimension of a variety of ecosystems. From these early studies it is clear that microbial cells in and on our bodies outnumber human cells by a factor of ten, and that the environments we inhabit are likewise teaming with microbial life. [9] Most modern studies on the microbiology of the built environment carried out to date have been descriptive in nature; and while this work has yielded useful insights into indoor microbial biodiversity (e.g. [10]), it has done little thus far to advance our understanding of the functional nature, ecological 
interactions, health and lifestyle implications, and building science determinants of the built environment as a microbial habitat [11].

\section{The Built Environment as a Microbial Habitat: General Trends}

It has long been known that members of the microbiota of indoor air and dust originate from a number of sources, including the outdoor environment (entrained in air entering through open doors and windows, and tracked in with soil particles and other debris on the feet of humans and pets), the activities of the building occupants (resuspension from floor dust during cleaning or other activities or from food preparation), and directly from the inhabitants themselves (dander, respiratory secretions, fecal deposits) [12]. Under normal circumstances, most microbes remain inactive in dusts or on surfaces; however, under suitable conditions, certain amongst them may establish metabolically active, proliferating populations. These phenomena and many of their consequences have been reviewed extensively by Rintala et al. [3].

The interiors of human dwellings in temperate climates can be thought of, more or less, as tropical islands scattered across a seasonally varying landscape characterized by climatic fluctuations and parallel shifts in biological activity. Although this concept is not without precedent, having been applied to the built structures of other species [13], it warrants discussion here because the tropicalizing of the built environment is an historically recent phenomenon with consequences for our understanding of the microbial ecology of the modern built environment.

In the late 19th century, Carnelley et al. [7] reported an average, wintertime, indoor air temperature in houses in the Scottish town of Dundee of $12.5^{\circ} \mathrm{C}$. This is chilly by modern standards and, interestingly, the indoor air temperature did not vary by level of affluence. Since then, the interiors of residential houses in temperate climates have become even more differentiated from their surrounding environments. By the mid-20th century, as heating fuels became more readily accessible, houses grew warmer in the wintertime; however, mounting energy costs drove construction practices to build increasingly tighter and better insulated buildings [14]. It is noteworthy that the word "insulation" derives from the late Latin, insulāris meaning island [15]. Along with improvements to thermal comfort, the introduction of larger windows made houses brighter [14]. These physical changes to the built environment brought about biological changes, principally amongst our inquilines - those organisms with which we share our dwellings, both by design and coincidence. For example, the increasingly tropical quality of indoor spaces allowed the cultivation of houseplants, most of which are tropical in origin [16]. These changes likewise facilitated the introduction of tropical and subtropical animals in the form of pets as well as pests $[17,18]$. In all cases, the macroorganisms have undoubtedly been accompanied by myriads of microorganisms.

\section{Bacteria}

The bacterial microbiota of indoor dust is dominated by Grampositive taxa, with the most commonly identified phyla in floor and mattress dust corresponding to those associated with the human skin and gut, mainly Proteobacteria, Firmicutes, and Actinobacteria [3]. Members of the phylum Bacteroidetes predominate in indoor air $[3,19]$. These microbes are generally considered to represent pseudopopulations because, with the exception of certain actinomycetes (particularly Streptomyces spp.), it is generally thought that water activity in house dust and on most indoor surfaces is too low to support bacterial proliferation [20].

In a study of 40 homes in North Carolina, Dunn et al. collected environmental samples from multiple indoor locations and documented a series of housing characteristics such as the number of human occupants, presence of cats, presence of children, use of pesticides, and presence of carpet [21]. They confirmed the chief contribution of the human microbiome to the indoor bacterial load, and in addition, they revealed that the home over time develops the unique microbial imprint of its occupants [21]. Perhaps in part owing to this strong "founder effect", they failed to discern any influence of the measured housing characteristics on indoor bacterial diversity.

Modern sequence-based methods have also permitted investigations of the movement of microbes within indoor environments. In an unusual examination of this effect, Jeon et al. studied the contribution of toileting activities to the bacterial burden on refrigerated vegetables [22]. Although their primary focus was the identification of reservoirs of potentially pathogenic microbes, their work confirmed that a vast majority of indoor bacteria originate from the human microbiome. Toilet seat surfaces were dominated by skinassociated bacteria rather than gut bacteria, suggesting that touch may be more important in contributing bacteria to this surface than aerosol generation during toilet use. Over one fifth of the bacteria found in residential kitchen refrigerators originate from the human microbiome, representing the skin and gut microbiota in a ratio of roughly $3: 1$ [22]. Although significantly different microbial communities were represented in samples from different locations within a home, samples from particular types of environments such as kitchens and frequently touched surfaces showed compositional similarities when compared between homes [21].

Just as the human microbiome contributes to the microbiota of the built environment, there is mounting evidence that 
the reciprocal is also true. House dust exposure mediates gut microbiome Lactobacillus enrichment and airway immune defense against allergens and virus infection [23]. The indoor environment can also serve as a mediator for the sharing of microbiota between cohabitating humans as well as their pets [24].

It is well known that moisture is a key mediator of the structure and composition of indoor fungal communities [2]; however, the degree to which this is true for bacteria remains less clear. Kettleson et al. used quantitative polymerase chain reaction to determine the degree that superfluous water in the form of water damage within a home fosters the indoor proliferation of bacteria [25]. They found a statistically significant correlation between the concentration of Stenotrophomonas maltophilia in house dust and the ERMI (Environmental Relative Moldiness Index) level of homes. When homes were divided into two groups based on the ERMI level, the authors determined that the Group 1 (water-damage) molds were associated with higher concentrations of $S$. maltophilia and Streptomyces spp. In addition, amid the multiple home variables investigated by the authors, surface moisture remained a strong determinant of $S$. maltophilia. The presence of dogs was a strong predictor for increased levels of Streptomyces and Mycobacterium, leading the authors to suggest that these genera may not represent endogenous populations but rather become tracked indoors by pets [25].

Vacuum cleaners have long been known to contribute to indoor bacterial aerosols primarily through the resuspension of bacteria already in the indoor environment $[5,26]$. In highrisk environments or for stringent cleaning, these devices are commonly outfitted with high-efficiency particulate air filters [2]. However, despite the presence of particle-arresting filters, the act of vacuum cleaning itself is known to release and resuspend dust [27, 28]. To investigate the influence of vacuum cleaner characteristics on indoor air microbiota, Knibbs et al. [29] collected samples of dust from the interior of inside vacuum cleaner collection bags and filters in addition to collecting samples of the emissions of aerosol and room air. Surprisingly, they found no relationship between the bacterial content of the vacuum cleaner bag and the bacterial emission. Similarly, the type of vacuum cleaner, price, and device age did not strongly influence the magnitude of the bacterial emission [29].

\section{Fungi}

The fungal component of indoor microbiota has been investigated in several recent studies using sequence-based methods. Amend et al. [10] sampled dust from 72 different building types across a wide geographic range. They found that latitude predicted the composition of indoor fungal microbiota to a greater extent than all other variables measured. They also observed an unexpected pattern whereby indoor fungal diversity increased as a function of distance from the equator, similar to the pattern suggested for ectomycorrhizal forest mushrooms [30]. To explain this effect, they noted that the use of integrative sampling captured both active and quiescent cells and thus represented spore burst originating across multiple seasons. Indeed, house dust is analogous to a soil seed bank, where the vast majority of its captive biodiversity is inactive, with most of the constituent propagules having dispersed from elsewhere and simply accumulated over time. The further tendency of houses at increasing latitude to function as microbial islands, as discussed above, contributes to indoor biological complexity. As discussed by van Bronswijk, dust contains multiple overlapping assemblages, inactive and active, allochthonous and autochthonous [12]. Without differentiating these assemblages, simple measures of intrinsic biodiversity greatly misreport ecological complexity.

A recent excellent paper by Yooseph et al. [31] developed a metagenomic framework approach (i.e., whole genome shotgun sequencing) to investigate biological diversity in air samples collected from buildings and outdoor air at two coastal locations: New York City and San Diego. Given the very low density of biological materials in air, they collected very large air volumes over time using SpinCon wet cyclone samplers and pooled the collections per site. The indoor sampling sites included a high-rise office building in New York City from which nearly $11,000 \mathrm{~m}^{3}$ air was collected. A hospital in San Diego yielded 3,100 $\mathrm{m}^{3}$ air, and a house, also in San Diego, provided $900 \mathrm{~m}^{3}$ air. All samples were carefully collected, prepared and extracted, and the recovered DNA was purified and subjected to whole genome shotgun sequencing. Taxonomies were assigned using a BLAST method, and the identities spanned a wide range of organism groups. Overall, nearly a third of all sequences they found represented members of the Eukarya and just over a fifth were bacteria. Nearly half of the sequences could not be assigned at the kingdom level. A summary of the 50 most commonly encountered indoor fungal genera is given in Table 1. In these samples, as expected, members of the genera Aspergillus and Penicillium are the most abundant indoor air fungi. Members of the lipophilic genus Malassezia were the 10th most common group (probably owing to the fact that the genus Homo predominated amongst eukaryotic sequences at $4 / 5$ sites) [31]. Striking, however, was the discovery in the indoor samples of human pathogenic fungi, particularly the endemic pathogens Ajellomyces and Coccidioides. Ajellomyces is the sexual state of species of Blastomyces and Histoplasma. Both agents are endemic in the northeast but not in the southwest. Thus, the finding of these genera at both indoor locations in San Diego is unexpected. Conversely, species of Coccidioides are endemic pathogens in the arid southwest extending into central and South America. Coccidioides species are not known to occur outside of that range, and thus the discovery of this 
Table 1 Summary of the 50 most commonly occurring, indoor, fungal genera based on a detailed metagenomic characterization of three indoor environments, based on the number of sequences recovered, after [31]

\begin{tabular}{|c|c|c|c|c|c|}
\hline \multirow[t]{2}{*}{ Genus } & \multirow[t]{2}{*}{ Habitat notes [37] } & \multirow[t]{2}{*}{ Sum of indoor samples } & \multicolumn{3}{|c|}{ Indoor environment (according to [31]) } \\
\hline & & & New York high rise & San Diego hospital & San Diego house \\
\hline Aspergillus & Soil, food & 22,792 & 16,628 & 5,424 & 740 \\
\hline Penicillium & Soil, fruit, seeds & 19,474 & 13,363 & 4,273 & 1,838 \\
\hline Laccaria & Mushroom: ectomycorrhizal & 14,890 & 14,457 & 362 & 71 \\
\hline Coprinopsis & Mushroom: lawn & 11,440 & 11,027 & 350 & 63 \\
\hline Phaeosphaeria & Plant leaf pathogen & 10,842 & 6,379 & 4,027 & 436 \\
\hline Botryotinia/Botrytis & Fruit rot & 7,577 & 6,010 & 1,456 & 111 \\
\hline Neosartorya & Compost colonist, human pathogen & 6,743 & 4,811 & 1,552 & 380 \\
\hline Sordaria & Dung, soil & 5,365 & 155 & 5,047 & 163 \\
\hline Filobasidiella & Wood saprotroph, human pathogen & 4,631 & 4,529 & 93 & 9 \\
\hline Malassezia & Skin colonist: lipophilic yeast & 4,476 & 3,515 & 783 & 178 \\
\hline Emericella & Soil, seeds, food & 3,944 & 2,523 & 1,184 & 237 \\
\hline Postia & Wood rot & 3,888 & 3,561 & 276 & 51 \\
\hline Gibberella & Plant pathogen, soil & 3,314 & 1,783 & 1,335 & 196 \\
\hline Talaromyces & Soil saprotroph & 3,118 & 2,435 & 581 & 102 \\
\hline Sclerotinia & Plant pathogen & 3,068 & 2,280 & 744 & 44 \\
\hline Chaetomium & Wood saprotroph: cellulose & 2,384 & 1,202 & 943 & 239 \\
\hline Ustilago & Plant parasite: obligate & 2,287 & 1,581 & 588 & 118 \\
\hline Podospora & Dung, soil & 1,849 & 1,114 & 621 & 114 \\
\hline Ajellomyces & Soil, human pathogen & 1,846 & 1,031 & 745 & 70 \\
\hline Neurospora & Soil, fire pit fungus & 1,751 & 965 & 664 & 122 \\
\hline Schizophyllum & Wood rot & 1,641 & 1,377 & 215 & 49 \\
\hline Magnaporthe & Plant pathogen & 1,533 & 899 & 572 & 62 \\
\hline Saccharomyces & Ascomycetous yeast, food spoilage & 1,523 & 712 & 77 & 734 \\
\hline Nectria & Wood saprotroph & 1,448 & 307 & 973 & 168 \\
\hline Moniliophthora & Saprotrophic mushroom & 1,393 & 1,213 & 171 & 9 \\
\hline Candida & Mammalian mucosa, food & 1,166 & 1,132 & 28 & 6 \\
\hline Lodderomyces & Yeast (mostly environmental) & 1,038 & 1,008 & 21 & 9 \\
\hline Coccidioides & Soil, human pathogen & 944 & 576 & 325 & 43 \\
\hline Arthroderma & Soil, human pathogen & 818 & 348 & 412 & 58 \\
\hline Uncinocarpus & Keratinophilic soil fungus & 558 & 293 & 240 & 25 \\
\hline Verticillium & Soil, fungal parasite & 511 & 91 & 354 & 66 \\
\hline Phanerochaete & Wood rot & 433 & 395 & 36 & 2 \\
\hline Debaryomyces & Yeast & 371 & 354 & 15 & 2 \\
\hline Yarrowia & Yeast & 370 & 335 & 31 & 4 \\
\hline Clavispora & Yeast & 337 & 330 & 7 & - \\
\hline Meyerozyma & Yeast & 331 & 314 & 12 & 5 \\
\hline Scheffersomyces & Yeast & 275 & 259 & 11 & 5 \\
\hline Schizosaccharomyces & Ascomycetous yeast ("fission yeasts") & 273 & 147 & 90 & 36 \\
\hline Mycosphaerella & Wood saprotroph, plant pathogen & 223 & 68 & 146 & 9 \\
\hline Trametes & Wood rot & 213 & 213 & - & - \\
\hline Pleurotus & Wood rot fungus & 194 & 183 & 11 & - \\
\hline Alternaria & Phylloplane & 191 & 69 & 120 & 2 \\
\hline Claviceps & Plant parasite - obligate & 155 & 98 & 45 & 12 \\
\hline Hуростеа & Fungal parasite & 146 & 60 & 47 & 39 \\
\hline Cladosporium & Phylloplane, some halophiles & 144 & 10 & 95 & 39 \\
\hline Tricholoma & Mushroom & 126 & 105 & 21 & - \\
\hline
\end{tabular}


Table 1 (continued)

\begin{tabular}{|c|c|c|c|c|c|}
\hline \multirow[t]{2}{*}{ Genus } & \multirow[t]{2}{*}{ Habitat notes [37] } & \multirow[t]{2}{*}{ Sum of indoor samples } & \multicolumn{3}{|c|}{ Indoor environment (according to [31]) } \\
\hline & & & New York high rise & San Diego hospital & San Diego house \\
\hline Davidiella & Wood saprotroph & 110 & 6 & 99 & 5 \\
\hline Fusarium & Soil saprotroph, plant pathogen & 96 & 39 & 55 & 2 \\
\hline Leptosphaeria & Wood saprotroph & 89 & 35 & 28 & 26 \\
\hline
\end{tabular}

NB: Genera in bold contain species encountered regularly as human pathogens or commensals

genus in New York City is indeed surprising and warrants further consideration.

In a study using gravity settling air samples, Adams et al. determined that, like bacteria, indoor airborne fungi largely originate from outdoor air in the absence of indoor dampness [32]. They suggested that the amount of fungal growth and resuspension occurring indoors is insufficient to lead to differentiation in fungal populations between rooms, so that the difference between rooms is likely explained by the infiltration of outdoor air rather than indoor proliferation. Many of the identified taxa had a clear outdoor origin, including plant pathogens, lichenized fungi, mushrooms, and puffballs. Passive gravity-based samplers inefficiently capture small-spored fungi leading to their under-representation relative to largerspored taxa [33]. This sampling method seems a highly unusual choice and not at all aligned with developments in modern sampling technologies (i.e., post-1940s). It is unclear if this effect influenced the results of this study; however, the sole factor in their model able to explain the structure of the indoor fungal communities was spatial position. No indicator taxa were identified that corresponded to particular room types [32].

With the knowledge that a majority of indoor fungi originate from outdoor air, the authors sampled within the university housing units seeking to determine if certain areas, specifically at windowsills, drains, and the foreheads of the occupants, could act as fungal reservoirs [34]. Ultimately, they found that inanimate surfaces tend to be depositional environments and that in buildings without reported mold problems, these areas are not a dominant source for indoor fungal aerosols. While the community composition of each sample surface area was distinct as determined by Nonmetric Multidimensional Scaling, the only predictors of the fungal composition were sample type and room function (kitchen, bathroom). Thus, selective deposition likely explained the unique differences observed between sample types [34].

One consistent finding in recent literature on the indoor fungal microbiome is the unexpected magnitude of the contribution of the human microbiome, notably by members of the basidiomycetous genus Malassezia, a group of lipophilic yeast-like commensals associated with mammalian skin [10, $31,32,35]$. Together with a species of another under-reported dust-borne basidiomycete, the osmophilic genus Wallemia, these fungi are amongst the most common and prolific taxa in the indoor environment, potentially accounting for a significant proportion of the fungal biomass of house dust $[10,35$, 36]. The fact that both taxa have long remained unreported or underreported is most likely because of their troublesome cultivation (members of the genus Wallemia are strongly osmophilic [37] whereas most Malassezia species have obligate nutritional dependencies on exogenous lipids [38]).

The cell walls of most fungi consist of a matrix of fibrillar polysaccharides dominated by chitin and a mixture of glucans of which $\beta$-(1,3)-D-glucan is the most common form, although other glucan forms may be present [2]. The specific glucan composition of the fungal cell wall varies by species and cell type $[39,40]$. Glucans induce a proinflammatory response in humans exposed to glucan-rich dust [41]. Accordingly, they are recognized as important contributors to health effects arising from exposure to indoor dampness and mold and are routinely measured in population health studies related to the built environment [2]. There is a suggestion that $\beta$-(1,6)-D-glucan may be an even more potent immune modulator than $\beta-(1,3)$-D-glucan, albeit acting through a different receptor [42]. The relative contribution of Wallemia and Malassezia to dust may account for some of the mixed findings on the influence of environmental glucan exposures on health [43].

\section{Influence of Building Characteristics}

Over one and a quarter century ago, a landmark paper written by Carnelley et al. [7] examined several different building types, residential homes (60), schools (68), factories (4), and one hospital (4 wards). Building type was found to strongly influence microbial burden with interior air volume being negatively correlated to microbial load. The authors noted compositional differences between the different environments they sampled, reflecting the particular activities undertaken inside (e.g., repeated isolation of high numbers of mold colonies with a characteristically similar appearance was observed in air samples from a jute mill but not elsewhere). The levels of bacteria in indoor air varied positively in response to 1) 
occupancy, 2) human activity (and after a lag), 3) daytime, and 4) outdoor bioaerosol-releasing phenomena.

Using modern sequence-based methods, Meadow et al. [44] investigated the contribution of outdoor air to indoor air bacterial levels in university classrooms, both vacant and during occupancy, over a 9-day period. Some rooms received night-time ventilation through open windows while others received only mechanical ventilation. Inexplicably, actual air exchange rates were not measured. Substantial overlap was observed between the indoor air and outdoor air bacterial communities, and the phylogenetic diversity of outdoor air closely followed that of the indoor air during the sampling period. For example, a community shift in the outdoor air was also observed in the indoor air of the window-ventilated rooms at the same time points, while the building-ventilated rooms did not show the same community shift until $16 \mathrm{~h}$ later when the ventilation dampers were opened. It was noted that room occupancy was a significant predictor of the community composition in indoor air, with human-associated bacteria significantly higher in indoor air than outdoor air; however, the human-associated contribution to the indoor airborne microbial community was less important than ventilation and air source [44]. Despite its technological sophistication, this study adds little if anything to the much earlier findings of Carnelley et al. [7].

Another study of indoor microbiota in university classrooms similarly identified the outdoor air as a source of indoor air microbiota, but provided more detail on the additional anthropogenic contribution. Hospodsky et al. [45] identified broad similarities among the outdoor and indoor aerosol bacterial ecology with the presence of many environmentally associated organisms. In contrast to the findings of Meadow et al. [44], human occupancy was found to be the main factor influencing the concentration of bacteria in indoor air. They found that indoor air, the ventilation duct supply air, and floor dust all showed heavy representation from dominant bacteria associated with human skin, hair, and nostrils. Further, they found that oral cavity bacteria contributed less than human skin bacteria to airborne bacterial burden. Unexpectedly, the microbiota of floor dust closely resembled the air microbiota; previous studies have noted that the floor dust bacteria most closely resemble the human skin microbiome and differ substantially from the bacterial content of air. They concluded that the human-associated bacterial contribution to the indoor microbiome is variable and may be influenced by environmental factors such as the building design and conditions of use [45].

Environmental variables were characterized in greater detail in a study by Kembel et al. [46] looking at the effect of ventilation and design in hospital rooms on airborne bacterial microbiota. Like the other studies described above, this work also demonstrated the key importance of outdoor air as a contributor to the indoor air microbiome. However, these workers also revealed that certain environmental variables can affect the microbial composition of different rooms served by a common ventilation system. For example, bacterial communities of passively ventilated rooms were more similar to those of mechanically ventilated rooms under conditions of higher temperature, lower relative humidity, and lower air flow rates. Further, they identified the ventilation source to be the main modifier of airborne bacterial community structure $\left(\mathrm{R}^{2}=0.66, p=0.01\right)$. Environmental condition also influenced bacterial community structure, albeit to a lesser extent. Thus, despite the fact that open windows allow for the infiltration of outdoor air microbes, the mechanically ventilated nature of a room functions primarily to drive the bacterial diversity of the room air [46].

\section{Conclusions}

Although the application of high-throughput, next-generation, DNA sequencing methods to the characterization of the microbiology of the built environment remains in its infancy, these methods offer tremendous promise to improve our knowledge of building ecology and environmental health. Some key shortcomings of the emerging literature on this subject stem from a lack of integration with other areas of specialty, such as building science, materials engineering, industrial hygiene, and population health, whose existing technological platforms and long traditions of studying the built environment could benefit tremendously from the power offered by these sophisticated culture-independent techniques. For the study of the microbiology of the built environment to continue to grow and flourish, the focus of modern research must shift away from simple, technologically reliant, descriptive accounts of indoor microbes to the application of these methods to important basic and applied research questions in which environmental, engineering, and health outcome variables have all been measured and characterized with a similarly high level of resolution and sophistication.

Acknowledgments We are grateful to the Alfred P. Sloan Foundation and AllerGen NCE for providing financial support for this review and our work on the microbiology of the built environment. Dr. Shibu Yooseph (J. Craig Venter Institute) kindly facilitated access to metagenomic fungal datasets from reference [31] and provided comments on the mycological findings. Professor Brian Flannigan (Napier University, Edinburgh) generously acquainted us with the classic Carnelley et al. paper and provided many helpful insights into building microbiology.

\section{References}

1. Dobell C, van Leeuwenhoek A. Antony van Leeuwenhoek and his "little animals" being some account of the father of protozoology and 
bacteriology and his multifarious discoveries in these disciplines. New York: Dover Publications; 1960.

2. Flannigan B, Samson RA, Miller JD. Microorganisms in home and indoor work environments diversity, health impacts, investigation and control. 2nd ed. Boca Raton: CRC Press; 2011.

3. Rintala H, Pitkaranta M, Taubel M. Microbial communities associated with house dust. Adv Appl Microbiol. 2012;78:75-120.

4. Amato JA. Dust: a history of the small and the invisible. Berkeley: University of California Press; 2001.

5. Bodanis D. The secret house: 24 hours in the strange and unexpected world in which we spend our nights and days. New York: Simon \& Schuster; 1986.

6. Ehrenberg CG. Passat-staub und Blut-Regen ein grosses organisches unsichtbares Wirken und Leben in des Atmosphäre. Berlin: Koniglichen Akademie der Wissenschaften; 1849.

7. Carnelley T, Haldane JS, Anderson AM. The carbonic acid, organic matter, and micro-organisms in air, more especially of dwellings and schools. Phil Trans Royal Soc London B. 1887;178:61-111.

8. Townsend GL. Sir John Floyer (1649-1734) and his study of pulse and respiration. J Hist Med Allied Sci. 1967;22(3):286-316.

9. National Research Council (U.S.), Committee on Metagenomics: Challenges and Functional Applications, National Academies Press (U.S.). The new science of metagenomics revealing the secrets of our microbial planet. Washington: National Academies Press; 2007.

10. Amend AS, Seifert KA, Samson R, Bruns TD. Indoor fungal composition is geographically patterned and more diverse in temperate zones than in the tropics. Proc Natl Acad Sci U S A. 2010;107(31): 13748-53.

11. Corsi RL, Kinney KA, Levin H. Microbiomes of built environments: 2011 symposium highlights and workgroup recommendations. Indoor Air. 2012;22(3):171-2.

12. van Bronswijk JEMH. House dust biology for allergists, acarologists and mycologists. Zoelmond: J.E.M.H. van Bronswijk; 1981.

13. Joseph GS, Seymour CL, Cumming GS, Cumming DHM, Mahlangu Z. Termite mounds as islands: woody plant assemblages relative to termitarium size and soil properties. J Veg Sci. 2013;24(4):702-11.

14. Schoenauer N. 6000 years of housing. 2nd ed. New York: W.W. Norton \& Company; 2000.

15. Hoad TF. The concise oxford dictionary of English etymology. Oxford: Oxford University Press; 1993.

16. Martin T. Once upon a windowsill: a history of indoor plants. Portland: Timber Press; 1988.

17. Diamond JM. Guns, germs, and steel the fates of human societies. 1st ed. New York: W.W. Norton \& Company; 1997.

18. Mallis A. Handbook of pest control. 9th ed. Cleveland: GIE Media Inc.; 2004.

19. Smith DP, Alverdy JC, Siegel JA, Gilbert JA. Design considerations for home and hospital microbiome studies. In: IOM (Institute of Medicine), editor. The science and applications of microbial senomics: workshop summary. Washington: The National Academies Press; 2013. p. 166-87.

20. Pietarinen VM, Rintala H, Hyvarinen A, Lignell U, Karkkainen P, Nevalainen A. Quantitative PCR analysis of fungi and bacteria in building materials and comparison to culture-based analysis. J Environ Monit. 2008;10(5):655-63.

21. Dunn RR, Fierer N, Henley JB, Leff JW, Menninger HL. Home life: factors structuring the bacterial diversity found within and between homes. PLoS One. 2013;8(5):e64133.

22. Jeon YS, Chun J, Kim BS. Identification of household bacterial community and analysis of species shared with human microbiome. Curr Microbiol. 2013;67(5):557-63.

23. Fujimura KE, Demoor T, Rauch M, Faruqi AA, Jang S, Johnson C, et al. House dust exposure mediates gut microbiome Lactobacillus enrichment and airway immune defense against allergens and virus infection. Proc Natl Acad Sci U S A. 2014;111(2):805-10.
24. Song SJ, Lauber C, Costello EK, Lozupone CA, Humphrey G, BergLyons $\mathrm{D}$, et al. Cohabiting family members share microbiota with one another and with their dogs. Elife. 2013;2:e00458.

25. Kettleson E, Kumar S, Reponen T, Vesper S, Meheust D, Grinshpun SA, et al. Stenotrophomonas, Mycobacterium, and Streptomyces in home dust and air: associations with moldiness and other home/family characteristics. Indoor Air. 2013;23(5):387-96.

26. Scott JA, Malloch D, Wong B, Sawa T, Straus NA. DNA heteroduplex fingerprinting in Penicillium. Amsterdam: Harwood Academic; 2013. p. 225-36.

27. Buttner MP, Cruz-Perez P, Stetzenbach LD, Garrett PJ, Luedtke AE. Measurement of airborne fungal spore dispersal from three types of flooring materials. Aerobiologia. 2002;18(1):1-11.

28. Ferro AR, Kopperud RJ, Hildemann LM. Source strengths for indoor human activities that resuspend particulate matter. Environ Sci Technol. 2004;38(6):1759-64.

29. Knibbs LD, He CR, Duchaine C, Morawska L. Vacuum cleaner emissions as a source of indoor exposure to airborne particles and bacteria. Environ Sci Technol. 2012;46(1):534-42.

30. Tedersoo L, Nara K. General latitudinal gradient of biodiversity is reversed in ectomycorrhizal fungi. New Phytol. 2010;185(2):351-4.

31. Yooseph S, Andrews-Pfannkoch C, Tenney A, McQuaid J, Williamson S, Thiagarajan M, et al. A metagenomic framework for the study of airborne microbial communities. PLoS One. 2013;8(12): e81862.

32. Adams RI, Miletto M, Taylor JW, Bruns TD. Dispersal in microbes: fungi in indoor air are dominated by outdoor air and show dispersal limitation at short distances. ISME J. 2013;7(7):1262-73.

33. Scott JA, Summerbell RC, Green BJ. Detection of indoor bioaerosols. In: Adan OCG, Samson RA, editors. Fundamentals of mold growth in indoor environments and strategies for healthy living. Wageningen: Wageningen Academic Publishers; 2011. p. 353-79.

34. Adams RI, Miletto M, Taylor JW, Bruns TD. The diversity and distribution of fungi on residential surfaces. PLoS One. 2013;8(11): e78866.

35. Pitkaranta M, Meklin T, Hyvarinen A, Paulin L, Auvinen P, Nevalainen A, et al. Analysis of fungal flora in indoor dust by ribosomal DNA sequence analysis, quantitative PCR, and culture. Appl Environ Microbiol. 2008;74(1):233-44.

36. Nonnenmann MW, Coronado G, Thompson B, Griffith WC, Hanson $\mathrm{JD}$, Vesper S, et al. Utilizing pyrosequencing and quantitative PCR to characterize fungal populations among house dust samples. J Environ Monit. 2012;14(8):2038-43.

37. Ainsworth GC, Bisby GR, Kirk PM, Bioscience CABI. Ainsworth \& Bisby's dictionary of the fungi. P.M. Kirk, editor ... [et al.]; with the assistance of T.V. Andrianova, editor ... [et al.]. 10th ed. Wallingford: CABI; 2008.

38. Leeming JP, Notman FH. Improved methods for isolation and enumeration of Malasezzia furfur from human skin. J Clin Microbiol. 1987;25(10):2017-9.

39. Kruppa MD, Lowman DW, Chen YH, Selander C, Scheynius A, Monteiro MA, et al. Identification of $(1 \rightarrow 6)$-beta-D-glucan as the major carbohydrate component of the Malasezzia sympodialis cell wall. Carbohydr Res. 2009;344(18):2474-9.

40. Steele C, Rapaka RR, Metz A, Pop SM, Williams DL, Gordon $\mathrm{S}$, et al. The beta-glucan receptor dectin-1 recognizes specific morphologies of Aspergillus fumigatus. PLoS Pathog. 2005;1(4):e42.

41. Brown GD, Herre J, Williams DL, Willment JA, Marshall AS, Gordon S. Dectin-1 mediates the biological effects of beta-glucans. J Exp Med. 2003;197(9):1119-24. 
42. Noss I, Doekes G, Thorne PS, Heederik DJ, Wouters IM. Comparison of the potency of a variety of beta-glucans to induce cytokine production in human whole blood. Innate Immun. 2013;19(1):10-9.

43. Cherid H, Foto M, Miller JD. Performance of two different Limulus amebocyte lysate assays for the quantitation of fungal glucan. $\mathrm{J}$ Occup Environ Hyg. 2011;8(9):540-3.

44. Meadow JF, Altrichter AE, Kembel SW, Kline J, Mhuireach G, Moriyama $\mathrm{M}$, et al. Indoor airborne bacterial communities are influenced by ventilation, occupancy, and outdoor air source. Indoor Air. 2013. doi:10.1111/ina.12047.

45. Hospodsky D, Qian J, Nazaroff WW, Yamamoto N, Bibby K, Rismani-Yazdi H, et al. Human occupancy as a source of indoor airborne bacteria. PLoS One. 2012;7(4):e34867.

46. Kembel SW, Jones E, Kline J, Northcutt D, Stenson J, Womack AM, et al. Architectural design influences the diversity and structure of the built environment microbiome. ISME J. 2012;6(8):1469-79. 